\title{
Business Process Analysis of Drug Sales Management Based on Modified Petri Net
}

\author{
Ying $\mathrm{Fu}$ \\ School of Economics and Management \\ Beijing Jiaotong University \\ Beijing, China
}

\author{
Xindi Wang \\ School of Economics and Management \\ Beijing Jiaotong University \\ Beijing, China
}

\begin{abstract}
In this paper, taking the business process of drug sales management in enterprise $A$ as an example, a method of modified Petri net is proposed. Cost and human are introduced into the transitions of time Petri net, and time-cost-human Petri net is constructed. Then, based on the modified Petri net, cost and Manpower Capacity are introduced into the reachability tree and a "Cost and Manpower Capacity State Reachable Tree" is proposed, and a strict mathematical definition is given. The cumulative cost and Manpower Capacity of each reachable path transition sequence in Petri net can be calculated by means of the analysis method of "Cost and Manpower Capacity State Reachable Tree", thus the maximum value of cost and Manpower Capacity in the process can be obtained, and the cost and human resource performance of the business process model can be further analyzed. It makes up for the shortage of time Petri net in analyzing business process.
\end{abstract}

Keywords-sales management business process; time-costhuman Petri net; Cost and Manpower Capacity State Reachable Tree

\section{INTRODUCTION}

The business process of drug sales management in pharmaceutical enterprises studied in this paper refers to a series of orderly activities taken by enterprises in order to make drugs reach distributors smoothly on time, in quantity and in quality. With the increasingly fierce competition in the market, it is very difficult for pharmaceutical enterprises to form differentiated competitive advantages in terms of quality, price and performance. Therefore, how to efficiently complete the export of drugs is the key to the success of pharmaceutical enterprises. Therefore, pharmaceutical enterprises must attach importance to business process management. Petri net combines intuitive graphical representation with rigorous mathematical logic, which is very suitable for the modeling of discrete event systems. At present, most scholars choose to establish time Petri nets to analyze the operational efficiency of the whole business process. W.M.P first introduced how to build business process model using Petri net [1]. Guobin Hong used SPN to model business processes, and introduced the application of SPN in business process optimization [2]. Yanshan $\mathrm{Li}$ used workflow technology to analyze and reengineer the drug sales process of pharmaceutical enterprises [3]. But for the business process of pharmaceutical enterprises, it is not enough to analyze the whole business process only.
Because a large number of human resources and operating costs are often needed in the process of drug sales management business process execution, and if enterprises want to make profits, they must allocate various resources reasonably, in order to maximize the efficiency of enterprises by maximizing the utilization rate of human resources and minimizing operating costs. Therefore, it is necessary to optimize the cost and human resources allocated for each process link. At this time, it is necessary to need a model that can reflect the change of cost and manpower information in the system to solve this kind of problem, and time Petri net has limitations in the analysis of cost and manpower. So this paper optimizes the cost and manpower of time Petri net to improve the ability of Petri net to solve practical problems.

\section{CURRENT SituATION OF ENTERPRISE A}

$\mathrm{Y}$ Group, owned by Enterprise A, is a European pharmaceutical group with more than 20 varieties of drugs, 6,000 employees worldwide, and achieved sales of 95.3 billion euros in 2006. As one of the subsidiaries of Y Group in China, Enterprise A is mainly responsible for the wholesale, import and export of pharmaceuticals, medical devices and health care products and related consulting and service business in China. Enterprise A consists of Commercial Strategy and Operations Department, Finance Department, Commercial Supply Chain Department, Quality Assurance Department and Logistics Department. This paper focuses on the business process of drug sales management. In the implementation of the business process, the responsibilities of each department are listed in "Table I". 
TABLE I.

DEPARTMENT DUTIES

\begin{tabular}{|c|c|}
\hline Department & Responsibilities \\
\hline $\begin{array}{l}\text { Commercial Strategy } \\
\text { Operations Department }\end{array}$ & $\begin{array}{l}\text { Responsible for developing annual delivery plan and rolling sales forecast monthly, and comparing actual } \\
\text { delivery quantity with annual delivery forecast. }\end{array}$ \\
\hline $\begin{array}{l}\text { Commercial Supply chain and } \\
\text { Finance Department }\end{array}$ & $\begin{array}{l}\text { Responsible for establishing sales contract and filling in "drug sales record". Ensure that the quality } \\
\text { assurance agreement has been signed with the dealer. }\end{array}$ \\
\hline $\begin{array}{l}\text { Quality } \quad \text { Assurance } \\
\text { Department/Logistics Department }\end{array}$ & $\begin{array}{l}\text { Responsible for timely and properly delivering drugs and providing relevant documents for distributors } \\
\text { and related departments according to regulations. }\end{array}$ \\
\hline Finance Department & Responsible for auditing the qualification of the distributors. Draft and audit quality assurance agreement. \\
\hline
\end{tabular}

Through field research, the business process of drug sales management in Enterprise A is drawn as shown in "Fig. 1".

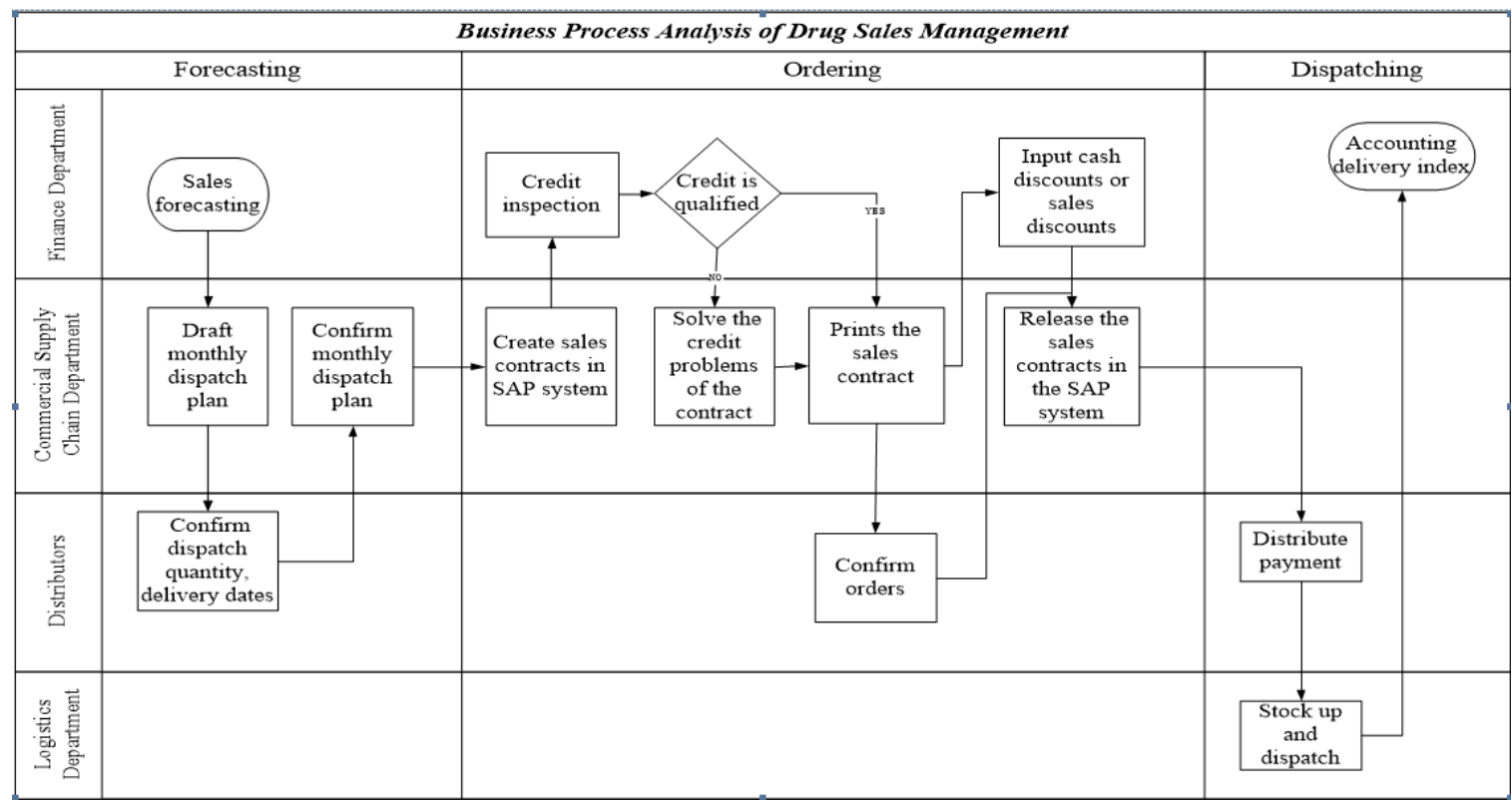

Fig. 1. Business process analysis of drug sales management.

\section{CONSTRUCTION OF TIME COST MANPOWER PETRi Net MODEL}

As can be seen from "Fig. 1", the business process of drug sales management in Enterprise A can be divided into three stages: forecasting stage, creating order stage and dispatching stage. Establish the time-cost-manpower Petri net model of the whole system according to the business flow chart of each stage as shown in "Fig. 2".

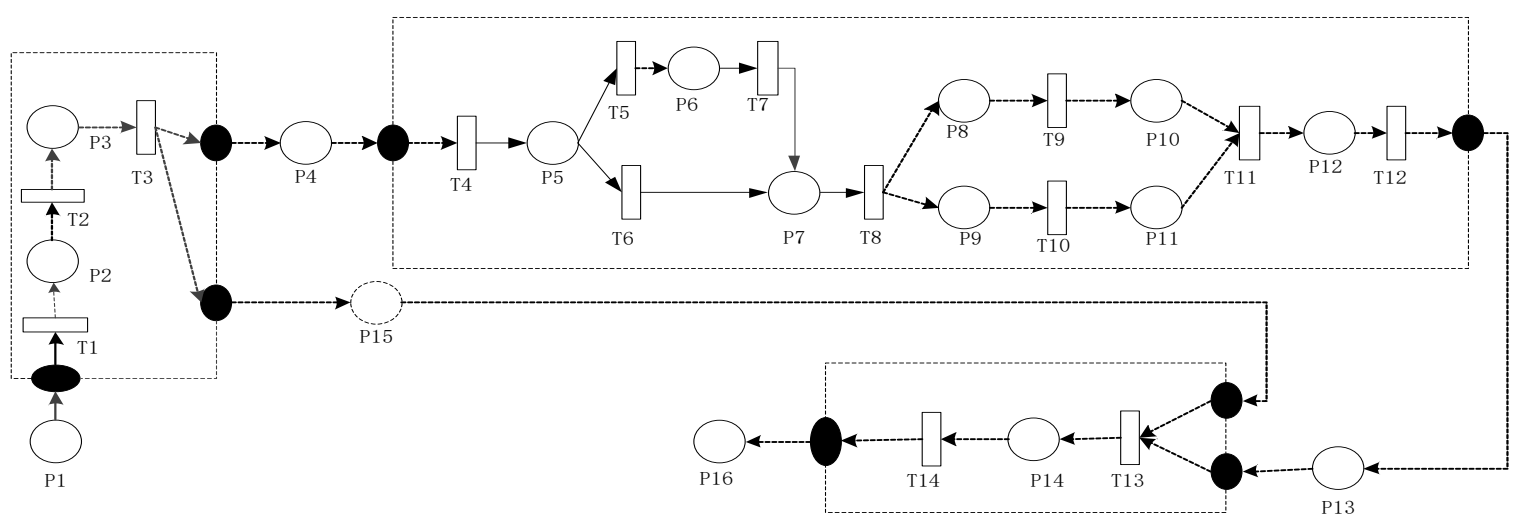

Fig. 2. Time-cost-human Petri Net. 
The meanings of places and transitions in modified Petri nets and the time delays of transitions are shown in "Table II" below.

Next, an association matrix can be conducted to verify the correctness of the Petri net in this paper. The corresponding correlation matrix is as follows:

$$
A=\left[\begin{array}{cccccccccccccc}
-1 & 0 & 0 & 0 & 0 & 0 & 0 & 0 & 0 & 0 & 0 & 0 & 0 & 0 \\
1 & -1 & 0 & 0 & 0 & 0 & 0 & 0 & 0 & 0 & 0 & 0 & 0 & 0 \\
0 & 1 & -1 & 0 & 0 & 0 & 0 & 0 & 0 & 0 & 0 & 0 & 0 & 0 \\
0 & 0 & 1 & -1 & 0 & 0 & 0 & 0 & 0 & 0 & 0 & 0 & 0 & 0 \\
0 & 0 & 0 & 1 & -1 & -1 & 0 & 0 & 0 & 0 & 0 & 0 & 0 & 0 \\
0 & 0 & 0 & 0 & 1 & 0 & -1 & 0 & 0 & 0 & 0 & 0 & 0 & 0 \\
0 & 0 & 0 & 0 & 0 & 1 & 1 & -1 & 0 & 0 & 0 & 0 & 0 & 0 \\
0 & 0 & 0 & 0 & 0 & 0 & 0 & 1 & -1 & 0 & 0 & 0 & 0 & 0 \\
0 & 0 & 0 & 0 & 0 & 0 & 0 & 1 & 0 & -1 & 0 & 0 & 0 & 0 \\
0 & 0 & 0 & 0 & 0 & 0 & 0 & 0 & 1 & 0 & -1 & 0 & 0 & 0 \\
0 & 0 & 0 & 0 & 0 & 0 & 0 & 0 & 0 & 1 & -1 & 0 & 0 & 0 \\
0 & 0 & 0 & 0 & 0 & 0 & 0 & 0 & 0 & 0 & 1 & -1 & 0 & 0 \\
0 & 0 & 0 & 0 & 0 & 0 & 0 & 0 & 0 & 0 & 0 & 1 & -1 & 0 \\
0 & 0 & 1 & 0 & 0 & 0 & 0 & 0 & 0 & 0 & 0 & 0 & 1 & -1 \\
0 & 0 & 0 & 0 & 0 & 0 & 0 & 0 & 0 & 0 & 0 & 0 & -1 & 0 \\
0 & 0 & 0 & 0 & 0 & 0 & 0 & 0 & 0 & 0 & 0 & 0 & 0 & 1
\end{array}\right]
$$

By solving the matrix equation $A^{T} X=0$, the basic solution system of $X$ can be obtained as follows:

$$
\begin{aligned}
& X_{1}=[0,0,0,0,0,0,0,-1,1,-1,1,0,0,0,0,0]^{\mathrm{T}} \\
& X_{2}=[0,0,0,-1,-1,-1,-1,-1,0,-1,0,-1,-1,0,1,0]^{\mathrm{T}} \\
& X_{3}=[1,1,1,1,1,1,1,1,0,1,0,1,1,1,0,1]^{\mathrm{T}}
\end{aligned}
$$

From the basic solution system, it is known that there exists an integer vector $X$

$$
X=X_{1}+X_{2}+3 X_{3}=[3,3,3,2,2,2,2,1,1,1,1,2,2,3,1,3]
$$

To make $A^{T} X=0$ which proves that the Petri net has three properties: conservation, reachability and boundedness, so the model is an effective model.

TABLE II. The MeANING of Places AND Transitions

\begin{tabular}{|l|l|l|l|}
\hline Place & \multicolumn{1}{|c|}{ Meaning } & \multicolumn{1}{|c|}{ Transition } & \multicolumn{1}{|c|}{ Meaning } \\
\hline $\boldsymbol{P 1}$ & Dispatch target list & T1 & Confirm dispatch quantity and feedback sales forecast \\
\hline $\boldsymbol{P 2}$ & Commercial Channel District Manager & $\begin{array}{l}\text { Summarize the sales forecasts and develop monthly } \\
\text { dispatch plan }\end{array}$ \\
\hline $\boldsymbol{P 3}$ & The commercial supply chain supervisor & T3 & Freates sales contracts in SAP system \\
\hline $\boldsymbol{P 4}$ & Supply chain department & T4 & Inspection is qualified and release the contracts \\
\hline $\boldsymbol{P 5}$ & Finance department & T5 & Solve the credit problems of the contracts \\
\hline $\boldsymbol{P 6}$ & Commercial Channel District Manager, & T7 & Prints the sales contracts and annexes seal of contracts \\
\hline $\boldsymbol{P 7}$ & Supply chain department & T8 & Confirm contracts \\
\hline $\boldsymbol{P 8}$ & Distributors & T9 & Input cash discounts or sales discounts \\
\hline $\boldsymbol{P 9}$ & Finance department & T10 & Releases the sales contract in the SAP system \\
\hline $\boldsymbol{P 1 0}$ & Effective sales contracts & T11 & Distributors payment \\
\hline $\boldsymbol{P 1 1}$ & Cash discounts or sales discounts list & T12 & Stock up and dispatch \\
\hline $\boldsymbol{P 1 2}$ & Distributors & T13 & Accounting delivery index \\
\hline $\boldsymbol{P 1 3}$ & Logistics department & T14 & \\
\hline $\boldsymbol{P 1 4}$ & monthly dispatch plan & & \\
\hline $\boldsymbol{P 1 5}$ & Logistics department & & \\
\hline $\boldsymbol{P 1 6}$ & Finance department & & \\
\hline
\end{tabular}

\section{BASIC THEORY OF COST MANPOWER CAPACITY STATE TREE ANALYSIS}

Based on the knowledge of related cost in finance, this paper divides the operation cost of transition into fixed cost and variable cost, which is recorded as $C=(V C ; F C)$. Fixed cost represents the cost when transition occurs and has nothing to do with other factors. Variable costs represent the cost of a unit time. The time of transition is expressed by the letter $t$, so the cost of each change can be recorded as: $T C=$ $V C * t+F C$.

In economics, production function is a function of output on input resources. According to the principle of production function in economics, with the increasing input of resources, the average output first increases to the maximum value and then decreases gradually [4]. Therefore, there is a point that the input of resources makes the average output maximum, which is also the ideal point of production for enterprises. Therefore, this paper regards human resources as a kind of resources invested by pharmaceutical enterprises, and uses the production function of economy for reference to calculate the output related to human resources in each transition, that is, Manpower Capacity (MC). Then MC is the quadratic function of human resources. In order to conform to the actual situation, this paper will set up a real number interval for the human resources associated with transition, which is recorded as $H=(m, n)$, then the MC function is recorded as $M C=-\alpha H^{2}+\beta H+\lambda$, where $\alpha>0, \beta / 2 \alpha>0,(-4 \alpha \lambda-\beta 2) /(-4 \alpha)>0$. 
Reachable tree is a method to analyze Petri net model. It can represent the resource flow of each mark, and it can also be observed intuitively that there are several reachable transition sequences in Petri net. In this paper, cost and MC are introduced into the reachable tree to establish an analysis method of "Cost and Manpower Capacity State Reachable Tree". The "Cost and Manpower Capacity State Reachable Tree" constructed by this method can intuitively show that there are several reachable paths in the model, and the path with the least cost and the largest MC can also be found through comparison.

Next, a strict mathematical definition of terms related to the "Cost and Manpower Capacity State Reachable Tree" is given.

Definition 1 (Cost and Manpower Capacity State, CMCS) Quaternion $c m c s=(\mathrm{M}$, enable (M), TC, HP)

$\mathrm{M}$ is the corresponding mark of the current CMCS. The initial mark is $\mathrm{M}_{0}$

Enable (M) is the set of all transitions that can be authorized to occur under the mark state $\mathrm{M}$.

TC is the cumulative cost of running the model from initial mark $\mathrm{M}_{0}$ to current mark status $\mathrm{M}$.

HP is the cumulative MC of the model from the initial mark $\mathrm{M}_{0}$ to the current mark status $\mathrm{M}$.

Definition 2 (Cost and Manpower Capacity State Calculating Method) In the modified Petri net, each transition $\mathrm{T} \epsilon$ enable (M) occurs, the corresponding CMCS will change. Let $c m c s=(\mathrm{M}$, enable $(\mathrm{M}), \mathrm{TC}, \mathrm{CHP})$ be the CMCS before change, and $c m c s^{\prime}=\left(\mathrm{M}^{\prime}\right.$, enable $(\mathrm{M})^{\prime}, \mathrm{TC}$, CHP') be the CMCS after change.

$\mathrm{M}^{\prime}=\mathrm{M}-* \mathrm{~T}+\mathrm{T}^{*}, \mathrm{~T}$ is the transition currently entitled to take place.

Enable (M') is a set of all transitions that can be authorized to occur under the mark state $\mathrm{M}^{\prime}$.

$\mathrm{TC}^{\prime}$ is the cumulative cost of cmcs', i.e. $\mathrm{TC}=\mathrm{TC}+\mathrm{VC}^{*} \mathrm{t}+\mathrm{FT}$. HP.

$\mathrm{CHP}^{\prime}$ is the cumulative $\mathrm{MC}$ of $c m c s^{\prime}$, i.e. $\mathrm{CHP}^{\prime}=\mathrm{CHP}+$

The specific calculation methods of MC are as follows:

If $\beta / 2 \alpha>n$, then $\mathrm{MC}=\left[-\alpha m^{2}+\beta m+\lambda,-\alpha n^{2}+\beta n+\lambda\right]$

If $\beta / 2 \alpha<m$, then $\mathrm{MC}=\left[-\alpha n^{2}+\beta n+\lambda,-\alpha m^{2}+\beta m+\lambda\right]$

If $m \leq \beta / 2 \alpha \leq n$, then $H P=\left[\min \left\{-\alpha n^{2}+\beta n+\lambda,-\alpha m^{2}+\beta m+\lambda\right\}\right.$, $(-4 \alpha \lambda-\beta 2) /(-4 \alpha)]$

Definition 3 (Cost and Manpower Capacity State Reachable Tree, CMCSRT) Triple $c m c s r t=(\mathrm{cmcs}, \mathrm{CF}, \mathrm{CT})$

cmcs is the current CMCS of modified Petri Nets

$\mathrm{CF}$ is a non-empty finite set of directed arcs. It is used to represent the flow direction between each CMCS.

CT is the set of transitions that make the CMCS change.

\section{Application of State Tree Analysis of Cost} AND MANPOWER CAPACITY State REACHABle TREE

According to the field survey, the parameters related to the modified Petri net transition are shown in "Table III".

TABLE III. PARAmeters RElated TO THE ModifIEd PETRI NeT

\begin{tabular}{|c|c|c|c|}
\hline Transition & Time & Cost & Human \\
\hline $\boldsymbol{I}$ & {$[1,3]$} & $(2 ; 4)$ & {$[0,1]$} \\
\hline $\boldsymbol{T 2}$ & {$[2,5]$} & $(1 ; 3)$ & {$[3,5]$} \\
\hline $\boldsymbol{T 3}$ & {$[1,3]$} & $(2 ; 5]$ & {$[1,2]$} \\
\hline $\boldsymbol{T 4}$ & {$[3,7]$} & $(1 ; 7)$ & {$[3,7]$} \\
\hline $\boldsymbol{T 5}$ & {$[0,2]$} & $(2 ; 4)$ & {$[2,5]$} \\
\hline $\boldsymbol{T 6}$ & {$[0,2]$} & $(1 ; 3)$ & {$[2,5]$} \\
\hline $\boldsymbol{T 7}$ & {$[0,2]$} & $(2 ; 6)$ & {$[0,1]$} \\
\hline $\boldsymbol{T} 8$ & {$[1,3]$} & $(2 ; 5)$ & {$[3,5]$} \\
\hline $\boldsymbol{T} 9$ & {$[1,3]$} & $(2 ; 7)$ & {$[2,5]$} \\
\hline $\boldsymbol{T 1 0}$ & {$[2,5]$} & $(1 ; 4)$ & {$[3,4]$} \\
\hline $\boldsymbol{T 1 1}$ & {$[0,1]$} & $(2 ; 5)$ & {$[3,5]$} \\
\hline $\boldsymbol{T 1 2}$ & {$[3,5]$} & $(3 ; 5)$ & {$[1,4]$} \\
\hline $\boldsymbol{T 1 3}$ & {$[2,5]$} & $(1 ; 4)$ & {$[4,5]$} \\
\hline $\boldsymbol{T 1 4}$ & {$[3,5]$} & $(2 ; 6)$ & {$[2,4]$} \\
\hline
\end{tabular}

Next, according to the analysis method of CMCSRT, the cumulative value of the cost and $\mathrm{MC}$ of each transition in the business process of drug sales management in Enterprise A is calculated, and the CMCSRT of the modified Petri net is constructed. Because the MC function is an empirical function derived from a large number of empirical data of enterprises, it is necessary to use the coefficient random generator to get the $\mathrm{MC}$ function as $\mathrm{MC}=-\mathrm{H} 2+4 \mathrm{H}+7$. The calculation steps are as follows:

First: under the initial state of cmcs0, $\mathrm{M} 0=(1,0,0,0,0,0,0,0,0,0,0,0,0,0,0,0), \quad$ enable $(\mathrm{M} 0)=\{\mathrm{T} 1\}$, $\mathrm{t}=(1,3), \mathrm{tc} 0=[2 ; 4], \mathrm{H} 0=[0,1], \mathrm{TC} 0=[0,0], \mathrm{CHP} 0=[0,0]$

Second: when the transition $\mathrm{T} 1$ is implemented, the arrival state cmcs $_{1}, \quad \mathrm{M}_{1}=(0,1,0,0,0,0,0,0,0,0,0,0,0,0,0,0)$, enable $\left(\mathrm{M}_{1}\right)=\{\mathrm{T} 2\}, \quad \mathrm{tc} 1=4+[1 ; 3] * 2=[6 ; 10], \quad \mathrm{MC}_{1}=[7,10]$, $\mathrm{TC}_{1}=[6 ; 10], \mathrm{CHP}_{1}=[7,10]$

Third: when the transition $\mathrm{T} 2$ is implemented, the arrival state $\quad$ cmcs $_{2}, \quad \mathrm{M}_{2}=(0,0,1,0,0,0,0,0,0,0,0,0,0,0,0,0)$, enable $\left(\mathrm{M}_{2}\right)=\{\mathrm{T} 3\}, \quad \mathrm{tc}_{2}=3+[2 ; 5] * 1=[5 ; 8], \quad \mathrm{MC}_{2}=[2,10]$, $\mathrm{TC}_{2}=[11 ; 18], \mathrm{CHP}_{2}=[9,20]$

Fourth: when the transition $\mathrm{T} 3$ is implemented, the arrival state $\mathrm{Cmcs}_{3}, \quad \mathrm{M}_{3}=(0,0,0,1,0,0,0,0,0,0,0,0,0,0,0,0)$, enable $\left(\mathrm{M}_{3}\right)=\{\mathrm{T} 4\}, \quad \mathrm{tc}_{3}=5+[1 ; 3] * 2=[7 ; 11], \quad \mathrm{MC}_{3}=[10,11]$, $\mathrm{TC}_{3}=[18 ; 29], \mathrm{CHP}_{3}=[19,31]$

Fifth: when the transition T4 is implemented, the arrival state $\quad$ cmcs $_{4}, \quad \mathrm{M}_{4}=(0,0,0,0,1,0,0,0,0,0,0,0,0,0,1,0)$, enable $\left(\mathrm{M}_{4}\right)=\{\mathrm{T} 5, \mathrm{~T} 6\} \mathrm{tc}_{4}=7+[3 ; 7] * 1=[10 ; 14], \quad \mathrm{MC}_{4}=[3,10]$, $\mathrm{TC}_{4}=[28 ; 43], \mathrm{CHP}_{4}=[21,41]$

Sixth: (1) When the transition T5 is implemented, the arrival state $\mathrm{cmcs}_{5}, \quad \mathrm{M}_{5}=(0,0,0,0,0,1,0,0,0,0,0,0,0,0,1,0)$, enable $\left(\mathrm{M}_{5}\right)=\{\mathrm{T} 7\}, \quad \mathrm{tc}_{5}=4+[0 ; 2] * 2=[4 ; 8], \quad \mathrm{MC}_{5}=[2,11]$, $\mathrm{TC}_{5}=[32 ; 51], \mathrm{CHP}_{5}=[23,52]$

(2) When the transition T7 is implemented, the arrival state $\quad$ cmcs $_{6}, \quad \mathrm{M}_{7}=(0,0,0,0,0,0,1,0,0,0,0,0,0,0,1,0)$, 
enable $\left(\mathrm{M}_{7}\right)=\{\mathrm{T} 8\}, \quad \mathrm{tc}_{6}=6+[0 ; 2] * 2=[6 ; 10], \quad \mathrm{MC}_{6}=[7,10]$, $\mathrm{TC}_{6}=[38 ; 61], \mathrm{CHP}_{6}=[30,62]$

(3) When the transition T8 is implemented, the arrival state $\quad \mathrm{cmcs}_{7}, \quad \mathrm{M}_{8}=(0,0,0,0,0,0,0,1,1,0,0,0,0,0,1,0)$, enable $\left(\mathrm{M}_{8}\right)=\{\mathrm{T} 9, \mathrm{~T} 10\}, \quad \mathrm{tc}_{7}=5+[1 ; 3] * 2=[7 ; 11], \quad \mathrm{MC}_{7}=[2,10]$, $\mathrm{TC}_{7}=[45 ; 72], \mathrm{CHP}_{7}=[32,72]$

(4) (1)When the transition T9 is implemented, the arrival state $\quad \mathrm{cmcs}_{8}, \mathrm{M}_{9}=(0,0,0,0,0,0,0,0,1,1,0,0,0,0,1,0)$, enable $\left(\mathrm{M}_{9}\right)=\{\mathrm{T} 10\}, \quad \mathrm{tc}_{8}=7+[1,3] * 2=[9 ; 13], \quad \mathrm{MC}_{8}=[2,11]$, $\mathrm{TC}_{8}=[54 ; 85], \mathrm{CHP}_{8}=[34,83]$

(2) When the transition T10 is implemented, the arrival state $\quad$ cmcs $_{10}, \quad \mathrm{M}_{11}=(0,0,0,0,0,0,0,0,0,1,1,0,0,0,1,0)$, enable $\left(\mathrm{M}_{11}\right)=\{\mathrm{T} 11\}, \quad \mathrm{tc}_{10}=4+[2,5] * 1=[6 ; 9], \quad \mathrm{MC}_{10}=[7,10]$, $\mathrm{TC}_{10}=[60 ; 94], \mathrm{CHP}_{10}=[41,93]$

(3) When the transition T11 is implemented, the arrival state $\quad$ cmcs $_{11}, \quad \mathrm{M}_{12}=(0,0,0,0,0,0,0,0,0,0,0,1,0,0,1,0)$, enable $\left(\mathrm{M}_{12}\right)=\{\mathrm{T} 12\}, \quad$ tc $11=5+[0,1] * 2=[5 ; 7], \quad \mathrm{MC}_{11}=[2,10]$, $\mathrm{TC}_{11}=[65 ; 101], \mathrm{CHP}_{11}=[43,103]$

(4) When the transition T12 is implemented, the arrival state $\quad$ cmcs $_{12}, \quad \mathrm{M}_{13}=(0,0,0,0,0,0,0,0,0,0,0,0,1,0,1,0)$, enable $\left(\mathrm{M}_{13}\right)=\{\mathrm{T} 13\}, \quad \mathrm{tc}_{12}=5+[3,5] * 3=[14 ; 20], \quad \mathrm{MC}_{12}=[7,11]$, $\mathrm{TC}_{12}=[79 ; 121], \mathrm{CHP}_{12}=[50,114]$

(5) When the transition T13 is implemented, the arrival state $\quad$ cmcs $_{13}, \quad \mathrm{M}_{14}=(0,0,0,0,0,0,0,0,0,0,0,0,0,1,0,0)$, enable $\left(\mathrm{M}_{14}\right)=\{\mathrm{T} 14\}, \quad \mathrm{tc}_{13}=4+[2,5] * 1=[6 ; 9], \quad \mathrm{MC}_{13}=[2,11]$, $\mathrm{TC}_{13}=[85 ; 130], \mathrm{CHP}_{13}=[52,125]$
(6) When the transition T13 is implemented, the arrival state $\quad$ cmcs $_{14}, \quad \mathrm{M}_{14}=(0,0,0,0,0,0,0,0,0,0,0,0,0,0,0,1)$, enable $\left(\mathrm{M}_{15}\right)=\varnothing, \quad \mathrm{tc}_{14}=6+[3,5] * 2=[12 ; 16], \quad \mathrm{MC}_{14}=[7,11]$, $\mathrm{TC}_{14}=[97 ; 146], \mathrm{CHP}_{14}=[59,136]$

The set of enabling transitions is empty. So far, the cost and MC of this path have been analyzed. Due to space limitation, the detailed calculation of the next path has been omitted. However, when constructing CMCRST, all the results are given as shown in "Fig. 3".

From the above analysis, it can be seen that the timecost- manpower Petri net model of drug sales management business process in pharmaceutical enterprise A triggers a series of transitions to make the CMCSRT from initial state M0 to final state M15. There are $23 \mathrm{cmcs}$ in this process, and the corresponding two paths of reachable transition are $\mathrm{L} 1: \mathrm{T} 1 \rightarrow \mathrm{T} 2 \rightarrow \mathrm{T} 3 \rightarrow \mathrm{T} 4 \rightarrow \mathrm{T} 5 \rightarrow \mathrm{T} 7 \rightarrow \mathrm{T} 8 \rightarrow \mathrm{T} 9 \rightarrow \mathrm{T} 10 \rightarrow \mathrm{T} 11 \rightarrow$ $\mathrm{T} 12 \rightarrow \mathrm{T} 13 \rightarrow \mathrm{T} 14$ and $\mathrm{L} 2: \mathrm{T} 1 \rightarrow \mathrm{T} 2 \rightarrow \mathrm{T} 3 \rightarrow \mathrm{T} 4 \rightarrow \mathrm{T} 6 \rightarrow \mathrm{T} 8 \rightarrow \mathrm{T} 9$ $\rightarrow \mathrm{T} 10 \rightarrow \mathrm{T} 11 \rightarrow \mathrm{T} 12 \rightarrow \mathrm{T} 13 \rightarrow \mathrm{T} 14$. From the CMCSRT, it is necessary to conclude that the maximum CHP and TC of these two paths are TC14 $=[97 ; 146]$, CHP14 $=[59,136]$, TC22 $=[90,130]$, CHP22 $=[52,128]$. Therefore, L2 is the path with the smallest operating cost and L1 is the path with the largest CHP. Based on this, it is necessary to manage and control the cost and human resource allocation of enterprise distribution process, and provide guidance for the performance analysis of enterprise actual business process. 


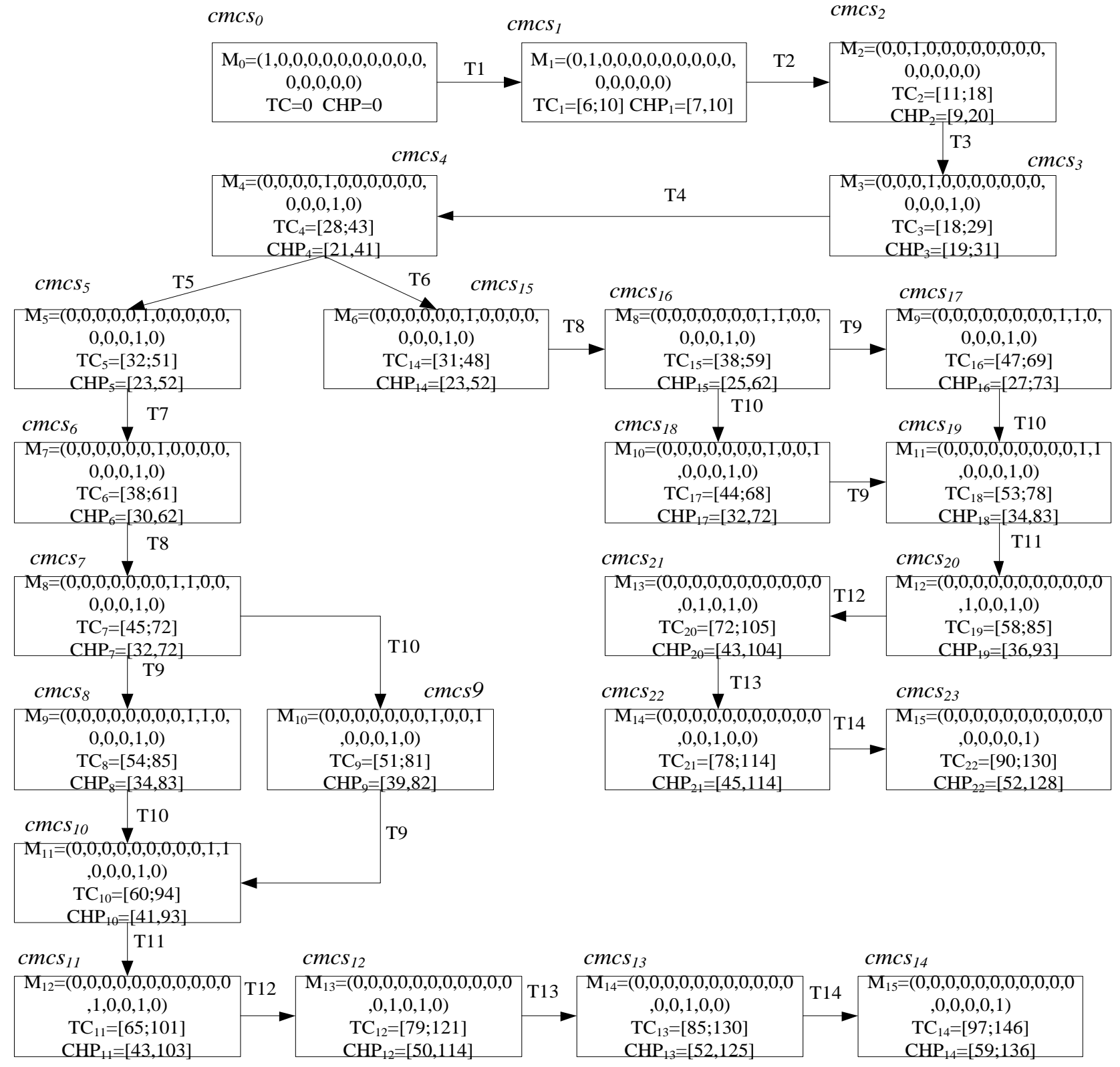

Fig. 3. Cost and manpower capacity state reachable tree.

\section{CONCLUSION}

In the current business competition tends to be white-hot environment, process management has become one of the core competitiveness of the organization. This paper constructs a time-cost-manpower Petri net which is more suitable for analyzing drug sales management business processes in pharmaceutical enterprises. A cost and Manpower Capacity state calculating method is proposed for the modified Petri net. This method can analyze the cost and human resource performance of business process model. Through the analysis of the reachable paths of the model, the maximum value of cost and CHP can be got in the process. At the same time, the cost and productivity value of the whole business process can be calculated, which can provide guidance for cost management, control and budget of enterprises. It enriches the analysis methods of process performance research. It provides support for further analysis, standardization and optimization of process.

\section{REFERENCES}

[1] VAN DER AALST W M P. The Application of Petri Nets to Workflow Management [J]. Journal of Circuits, Systems and Computers, 1998.08(01): 21-66.

[2] Guobin Hong, Bue Zheng. Research on Integration of Inter-firm Activity Relations Based on Petri Net [J]. Journal of Systems Engineering, 2005 (01): 43-48. 
[3] Yanshan Lin. Research on Business Process Reengineering of $\mathrm{X}$ Pharmaceutical Company [D]. Jinan University, 2010.77.

[4] Haiyang Song. Modeling and Resource Optimization of Resourceconstrained PETRI Network [D] ShangHai Jiaotong University, 2009.12 . 